\title{
Positive urinary fluorescence in situ hybridization indicates poor prognosis in patients with upper tract urothelial carcinoma
}

\author{
Bao Guan ${ }^{1,2, *}$, Yicong Du ${ }^{1,2, *}$, Xiaohong Su ${ }^{1,2, *}$, Zhenpeng $\mathrm{CaO}^{1}$, Yifan $\mathrm{Li}^{1,2}$, Yonghao \\ Zhan $^{1,2}$, Ding Peng ${ }^{1,2}$, Gengyan Xiong ${ }^{1,2}$, Dong Fang ${ }^{1,2}$, Yi Ding ${ }^{1}$, Shiming $\mathrm{He}^{1,2}$, \\ Yanqing Gong ${ }^{1,2}$, Qun $\mathrm{He}^{1,2}$, Xuesong $\mathrm{Li}^{1,2}$ and Liqun Zhou ${ }^{1,2}$ \\ ${ }^{1}$ Department of Urology, Peking University First Hospital, Xicheng, Beijing, China \\ ${ }^{2}$ Institute of Urology, Peking University, National Urological Cancer Center, Beijing, China \\ *These authors contributed equally to this work
}

Correspondence to: Xuesong Li, email: pineneedle@sina.com

Liqun Zhou, email: zhoulqmail@sina.com

Keywords: fuorescence in situ hybridization (FISH); upper tract urothelial carcinoma (UTUC); recurrence; prognosis

Received: July 20, 2017 Accepted: November 09, 2017 Epub: January 04, 2018 Published: March 06, 2018

Copyright: Guan et al. This is an open-access article distributed under the terms of the Creative Commons Attribution License 3.0 (CC BY 3.0 ), which permits unrestricted use, distribution, and reproduction in any medium, provided the original author and source are credited.

\section{ABSTRACT}

Here, we evaluated the potential contribution of fluorescent in situ hybridization (FISH) as a prognostic risk factor of bladder recurrence and survival in patients with upper tract urothelial carcinoma (UTUC). A total of 159 UTUC patients were enrolled in this study from January 2012 to May 2016. The 159 voided urine samples before surgery were analyzed using the UroVysion ${ }^{\circledR}$ kit to detect the copy numbers of chromosomes $3,7,17$ and 9p21 (p16). Patients were classified using an optimal cutoff value of chromosomes 3, 7, 17, and 9p21. Cox's proportional hazards regression model was used to assess the prognostic value of FISH for bladder recurrence and survival. We found that $27(17.6 \%)$ patients experienced bladder recurrence and $26(16.4 \%)$ patients died from cancer, with a median follow-up of 27 months. The patients with positive FISH result were more likely to present bladder recurrence $(p=0.077)$. However, positive FISH was not associated with cancer specific-free survival $(C S S)(p=0.944)$. Tumor multifocality, the percentage of abnormal chromosome $3>5 \%$, chromosome $7>6 \%$, chromosome $17>11 \%$ and deletion of p16 >4\% were significant prognostic risk factors for BRFS in univariate analysis. In multivariate analysis, only tumor multifocality (hazard ratio $[\mathrm{HR}]=3.487,95 \% \mathrm{CI}: 1.605-7.576, p=0.002$ ) and the percentage of p16 loss $>4 \%$ were both prognostic risk factors for bladder recurrence $(H R=3.487$, 95\%CI: 1.605-7.576, $p=0.002$ ). These data consider that the urinary FISH test could be a powerful tool in predicting the risk of bladder recurrence in patients with UTUC.

\section{INTRODUCTION}

Upper tract urothelial carcinoma (UTUC) is a relatively uncommon malignant tumor [1]. Though the standard treatment method, radical nephroureterectomy (RNU), could remove primary tumor lesions, the probability of bladder recurrence and progression remain high [1-3]. Consequently, it is necessary to find novel biomarkers to predict oncological outcomes.

Fluorescence in situ hybridization (FISH) analysis which uses nucleic acid probes marked with fluorescence to evaluate cells in the voided urine for chromosomal alterations and be widely applied to the field of cancer diagnosis. [4-7], and we had identified its high sensibility and prediction for advanced UTUC [8]. We used UroVysion ${ }^{\circledR}$ FISH test ((Abbott Molecular, des Plaines, IL, USA)) to measure the percentage of particular copy number variation of chromosomes $3,7,17$, and 9p21 (p16) in the urine. Recently, several studies had reported that FISH could be used as an aid to predict prognosis in bladder cancer patients [9-11], but its prognostic value had not yet been confirmed in UTUC patients. Therefore, the prognostic capacity of FISH was studied by us in a single and relatively high-volume center in China. 


\section{RESULTS}

\section{Patient and tumor characteristics}

There were $78(49.1 \%)$ male and $81(50.9 \%)$ female patients, and the median age was 70 years (range: 31-87 years). Among 159 patients, non-muscle invasive $(\leq \mathrm{pT} 1)$ and muscle invasive $(\geq \mathrm{pT} 2)$ UTUC patients were $82(51.5 \%)$ and $77(48.5 \%)$, respectively, while low and high grade patients were $86(54.1 \%)$ and 73 (45.9\%), respectively (Table 1).

\section{FISH results}

Clinical outcomes and cutoff value are described in Table 2. The median percentage of abnormal chromosome $3,7,17$ and p 16 loss were $7 \%(0-46 \%), 7 \%(0-38 \%), 8 \%$ $(0-53 \%)$ and $7 \%(0-65 \%)$, respectively. According to the area under the curve (AUC) from the receiver operating characteristic curve (ROC) for intravesical relapse, we defined the cutoff values of the proportion of aberrant chromosomes 3, 7, and 17 and loss of p16. The cutoff values were $5 \%$ for chromosome $3,6 \%$ for chromosome 7 , $11 \%$ for chromosome 17 and $4 \%$ for p16 loss. According to the cutoff values of preoperative factors, all patients were allocated to 2 classes.

The association of FISH with pathological tumor characteristic is shown in Table 3. Patients with percentage of chromosome $17>11 \%$ and loss of p16>4\% were associated with high stage and grade. Univariate and multivariate binary logistic analysis found only the percentage of abnormal chromosome 17 was associated with invasive UTUC (hazard ratio [HR] $=3.027,95 \% \mathrm{CI}$ : $1.059-8.650, p=0.015)$. Other preoperative factors did not show statistically significant differences.

\section{Oncological outcomes}

The median follow-up was 27 months (range: 3-55). The median time to bladder relapse and time to death from UTUC was 11 (range: 1-43 months) months and 15.5 (range: 3-38 months) months, respectively. During follow-up, $31(19.5 \%)$ patients died, 26 (16.4\%) of them due to UTUC; 28 (17.6\%) patients experienced bladder recurrence.

Variables associated with CSS and BRFS on univariate and multivariate analysis are shown in Table 4. The results of FISH analysis showed that 57 of 159 patients were negative, of 6 patients had histologically verified bladder recurrence; 102 patients were positive, of 22 had bladder recurrence. Kaplan-Meier analysis showed that patients with positive FISH result were more likely to present bladder recurrence ( $p=0.077$, Figure 1A). However, positive FISH was not related to cancer specific-free survival (CSS) $(p=0.944$, Figure 1B). Tumor multifocality, the percentage of abnormal chromosome $3>5 \%$, chromosome $7>6 \%$, chromosome $17>11 \%$ and deletion of $\mathrm{p} 16>4 \%$ were prognostic risk factors for BRFS in univariate analysis (Figure 2A-2D). Tumor multifocality (HR $=3.487,95 \%$ CI: $1.605-7.576$, $p=0.002)$ and $\mathrm{p} 16$ loss $>4 \%$ (HR $=3.766,95 \% \mathrm{CI}: 1.303$ $10.884, p=0.014$ ) were prognostic factors for BRFS in multivariate analysis. For CSS analysis, the percentage of abnormal chromosomes 3, 7, 17 and deletion of p16 were not prognostic factors in univariate analysis. Higher stage $(\mathrm{HR}=6.087,95 \% \mathrm{CI}: 2.766-13.395, p<0.001)$ and tumor size $>3 \mathrm{~cm}(\mathrm{HR}=2.425,95 \% \mathrm{CI}$ : $1.077-5.458$, $p=0.015)$ were independent prognostic factors for CSS in multivariate analysis.

\section{DISCUSSION}

UTUC is a comparatively rare cancer. The common diagnosis methods mainly included computed tomography/ magnetic resonance imaging, cystoscopy, urinary cytology and diagnostic ureteroscopy. About $15-25 \%$ of bladder lesions are muscle invasive, while $60 \%$ of UTUC are invasive at initial diagnosis as well as patients with UTUC had comparatively poor prognosis [12]. The prognostic factors for UTUC included acknowledged tumor stage and grade, lymphovascular invasion status, lymph node involvement, tumor size, hydronephrosis, tumor multifocality and necrosis [12]. In addition, European Association of Urology Guidelines reviewed several literatures and reported that four nomograms were currently available to predict survival rates post-operatively, based on standard pathological features [13-16]. Several studies had demonstrated that ureteroscopy increased the risk of bladder recurrence $[17,18]$, but urinary markers which could predict tumor recurrence were relatively few. Nobuyuki Tanaka et al. [19] retrospectively collected 474 patients with non-metastatic UTUC and found postoperative positive urine cytology was correlated with the occurrence rate of intravesical relapse after RNU. Kobayashi et al. [20] reported that urine cytology with positive result was a independent prognostic marker for intravesical relapse using a cohort of 252 UTUC patients. Our previous study [8] suggested that positive FISH result of urine implied invasive UTUC (sensitivity for muscleinvasive and high grade UTUC, $71.70 \%$ and $76.47 \%$, respectively) and this result gave aid to the clinical urological surgeon to select an appropriate operation method. However, the connection between FISH results and survival or progression of UTUC patients was unclear. Based on above study, we established this research to assess the influence of positive FISH on oncological outcomes in UTUC.

In this research, the results showed that patients with positive FISH were more likely to experience bladder recurrence. Casey Seideman et al. [11] reported that FISH result could accurately predict intravesical recurrence for those patients with bladder cancer. Jared Whitson et al. 
Table 1: Characteristics and outcomes of UTUC patients

\begin{tabular}{|c|c|}
\hline Variables & $N(\%)$ or Median (range) \\
\hline$N(\%)$ & 159 \\
\hline $\begin{array}{l}\text { Gender } \\
\quad \text { Male } \\
\text { Female }\end{array}$ & $\begin{array}{l}78(49.1) \\
81(50.9)\end{array}$ \\
\hline Age & $70(31-87)$ \\
\hline $\begin{array}{l}\text { Hydronephrosis } \\
\text { Present } \\
\text { Absent }\end{array}$ & $\begin{array}{l}19(11.9) \\
140(88.1)\end{array}$ \\
\hline $\begin{array}{l}\text { Tumor location } \\
\text { Pelvis } \\
\text { Ureter } \\
\text { Both }\end{array}$ & $\begin{array}{l}81(50.9) \\
71(44.7) \\
7(4.4)\end{array}$ \\
\hline $\begin{array}{l}\text { Tumor stage } \\
\text { A } \\
1 \\
2 \\
3 \\
4\end{array}$ & $\begin{array}{l}12(7.5) \\
70(44.0) \\
39(24.5) \\
37(23.3) \\
1(0.6)\end{array}$ \\
\hline $\begin{array}{l}\text { Tumor grade } \\
\text { Low } \\
\text { High }\end{array}$ & $\begin{array}{l}86(54.1) \\
73(45.9)\end{array}$ \\
\hline $\begin{array}{l}\text { Lymph node status } \\
\text { cN0 or pN0 } \\
\mathrm{N}+\end{array}$ & $\begin{array}{l}152(95.6) \\
7(4.4)\end{array}$ \\
\hline $\begin{array}{l}\text { LVI } \\
\qquad \text { Presence } \\
\text { Absence }\end{array}$ & $\begin{array}{l}139(87.4) \\
20(12.6)\end{array}$ \\
\hline $\begin{array}{l}\text { Tumor size } \\
\leq 3 \mathrm{~cm} \\
>3 \mathrm{~cm}\end{array}$ & $\begin{array}{l}90(56.6) \\
69(43.4)\end{array}$ \\
\hline $\begin{array}{l}\text { Multifocal } \\
\text { Yes } \\
\text { No }\end{array}$ & $\begin{array}{l}136(85.5) \\
23(14.5)\end{array}$ \\
\hline $\begin{array}{l}\text { FISH } \\
\quad \text { Positive } \\
\text { Negative }\end{array}$ & $\begin{array}{l}102(64.2) \\
57(35.8)\end{array}$ \\
\hline $\begin{array}{l}\text { FISH probe } \\
\qquad \begin{array}{l}\text { CH3 abnormal, \% } \\
\text { CH7 abnormal, \% } \\
\text { CH17 abnormal, \% } \\
\text { p16 loss, } \%\end{array}\end{array}$ & $\begin{array}{l}7(0-46) \\
7(0-38) \\
8(0-53) \\
7(0-65)\end{array}$ \\
\hline $\begin{array}{l}\text { Outcome } \\
\text { Follow-up, months } \\
\text { Time to recurrence, months } \\
\text { Time to death, months }\end{array}$ & $\begin{array}{l}27(3-55) \\
11(1-43) \\
15.5(3-38)\end{array}$ \\
\hline
\end{tabular}

$\mathrm{LVI}=$ lymphovascular invasion; FISH = fluorescence in situ hybridization; $\mathrm{CH}=$ chromosome 
Table 2: Clinical outcome in 159 assessable patients during median follow-up of 28 months

\begin{tabular}{|c|c|c|c|}
\hline FISH probe & $\mathrm{N}(\%)$ & Cancer specific death & Recurrence \\
\hline \multicolumn{4}{|l|}{$\overline{\text { FISH }}$} \\
\hline Positive & $102(64.2 \%)$ & $16(15.7 \%)$ & $22(21.6 \%)$ \\
\hline Negative & $57(35.8 \%)$ & $10(17.5 \%)$ & $6(10.5 \%)$ \\
\hline \multicolumn{4}{|c|}{ CH3 abnormal } \\
\hline$\leq 5 \%$ & $62(39.0)$ & $11(17.7 \%)$ & $5(8.1 \%)$ \\
\hline$>5 \%$ & $97(61.0)$ & $15(15.5 \%)$ & $23(23.7 \%)$ \\
\hline \multicolumn{4}{|c|}{$\mathrm{CH} 7$ abnormal } \\
\hline$\leq 6 \%$ & $77(48.4)$ & $15(19.5 \%)$ & $9(11.7 \%)$ \\
\hline$>6 \%$ & $82(51.6)$ & $11(13.4 \%)$ & $19(23.2 \%)$ \\
\hline \multicolumn{4}{|c|}{ CH17 abnormal } \\
\hline$\leq 11 \%$ & $98(61.6)$ & $15(15.3 \%)$ & $13(13.3 \%)$ \\
\hline$>11 \%$ & $61(38.4)$ & $11(18.0 \%)$ & $15(24.6 \%)$ \\
\hline \multicolumn{4}{|l|}{ p16 loss } \\
\hline$\leq 4 \%$ & $60(37.7)$ & $6(10.0 \%)$ & $4(6.7 \%)$ \\
\hline$>4 \%$ & $99(62.3)$ & $20(20.2 \%)$ & $24(24.2 \%)$ \\
\hline
\end{tabular}

FISH: fluorescence in situ hybridization; $\mathrm{CH}$ : chromosome.

Table 3: Preoperative factors that predict high-risk UTUC in univariate and multivariate analyses

\begin{tabular}{|c|c|c|c|c|c|c|c|c|}
\hline \multirow[t]{3}{*}{ Preoperative factors } & \multicolumn{4}{|c|}{ T2-T4 } & \multicolumn{4}{|c|}{ Tumor high grade } \\
\hline & \multicolumn{2}{|c|}{ Univariate } & \multicolumn{2}{|l|}{ Multivariate } & \multicolumn{2}{|c|}{ Univariate } & \multicolumn{2}{|l|}{ Multivariate } \\
\hline & $\mathbf{X}^{2}$ & $P$ & HR $(95 \%$ CI $)$ & $\boldsymbol{P}$ & $\mathbf{X}^{2}$ & $\boldsymbol{P}$ & HR $(95 \%$ CI $)$ & $\boldsymbol{P}$ \\
\hline Gender (male vs female) & 2.752 & 0.097 & $1.483(0.748-2.938)$ & 0.259 & 0.143 & 0.705 & $0.956(0.483-1.892)$ & 0.897 \\
\hline Age $(\leq 70$ vs $>70)$ & 1.388 & 0.239 & $1.562(0.797-3.063)$ & 0.194 & 2.191 & 0.139 & $1.696(0.869-3.310)$ & 0.122 \\
\hline Hydronephrosis (absence vs absence) & 1.875 & 0.171 & $0.517(0.479-4.322)$ & 0.517 & 0.018 & 0.892 & $1.283(0.442-3.724)$ & 0.647 \\
\hline Tumor location (both or ureter vs pelvis) & 1.239 & 0.538 & $1.679(0.392-1.366)$ & 0.327 & 3.915 & 0.141 & $1.518(0.820-2.813)$ & 0.184 \\
\hline Tumor size $(\leq 3 \mathrm{~cm}$ vs $>3 \mathrm{~cm})$ & 2.155 & 0.142 & $1.679(0.836-3.372)$ & 0.146 & 0.180 & 0.671 & $1.060(0.530-2.119)$ & 0.869 \\
\hline Multifocal (presence vs absence) & 0.705 & 0.401 & $1.167(0.451-3.018)$ & 0.751 & 1.219 & 0.270 & $1.529(0.592-3.950)$ & 0.381 \\
\hline $\mathrm{CH} 3$ abnormal $(\leq 5 \%$ vs $>5 \%)$ & 0.969 & 0.325 & $0.802(0.282-2.284)$ & 0.680 & 3.180 & 0.075 & $1.099(0.392-3.081)$ & 0.858 \\
\hline $\mathrm{CH} 7$ abnormal $(\leq 6 \%$ vs $>6 \%)$ & 1.855 & 0.173 & $0.584(0.179-1.906)$ & 0.373 & 2.905 & 0.088 & $0.674(0.210-2.160)$ & 0.506 \\
\hline $\mathrm{CH} 17$ abnormal $(\leq 11 \%$ vs $>11 \%)$ & 5.925 & 0.015 & $3.027(1.059-8.650)$ & 0.039 & 3.848 & 0.050 & $1.436(0.518-3.979)$ & 0.487 \\
\hline p16 loss $(\leq 4 \%$ vs $>4 \%)$ & 3.932 & 0.047 & $1.762(0.709-4.381)$ & 0.223 & 7.875 & 0.005 & $2.279(0.918-5.658)$ & 0.076 \\
\hline
\end{tabular}

$\mathrm{HR}=$ hazard ratio; $\mathrm{CI}=$ confidence interval; $\mathrm{CH}$ : chromosome.

[6] reported that patients with high-risk bladder deseases were more likely to relapse when they had positive FISH results. Massimo Maffezzini et al. [21] analyzed 126 patients diagnosed with non-muscle invasive bladder cancer (NMIBC) and observed that FISH-positive results was highly predictive of relapse. Our result determined the prognostic significance of FISH for predicting oncologic outcome. Recent fundamental research suggested that the luminal seeding and implantation hypothesis played a major role in bladder recurrence $[22,23]$. This hypothesis mainly asserted that the multifocal development including simultaneous and metachronous tumor was caused by the planting or intraepithelial diffusion tumor cells. Since positive FISH result were associated with higher stage and grade tumor which presented more aggressive, the patients with positive FISH result possibly had higher degrees of intravesical exposure. Therefore, it was reasonable that positive FISH patients tend to relapse in bladder.

In this cohort, we were the first to define the cutoff value of preoperative FISH test probe as a predictive indicator of bladder recurrence. In univariate analysis, tumor multifocality, the percentage of abnormal chromosome $3>5 \%$, chromosome $7>6 \%$, chromosome $17>11 \%$ and deletion of p16>4\% were correlated with BRFS. In multivariate analysis, only tumor multifocality and p16 loss $>4 \%$ were prognostic factors for BRFS. The 9p21 which contained p16/CDKN2 and p14ARF site located in chromosome 9 short arm and mainly participated in regulating cell circle and cell death $[24,25]$. The loss of 9p21 leads to the p16 gene non-functional, and then disorder cell cycle resulting in disease relapse [26]. Hideyasu Matsuyama et al. [10] identified 118 bladder 

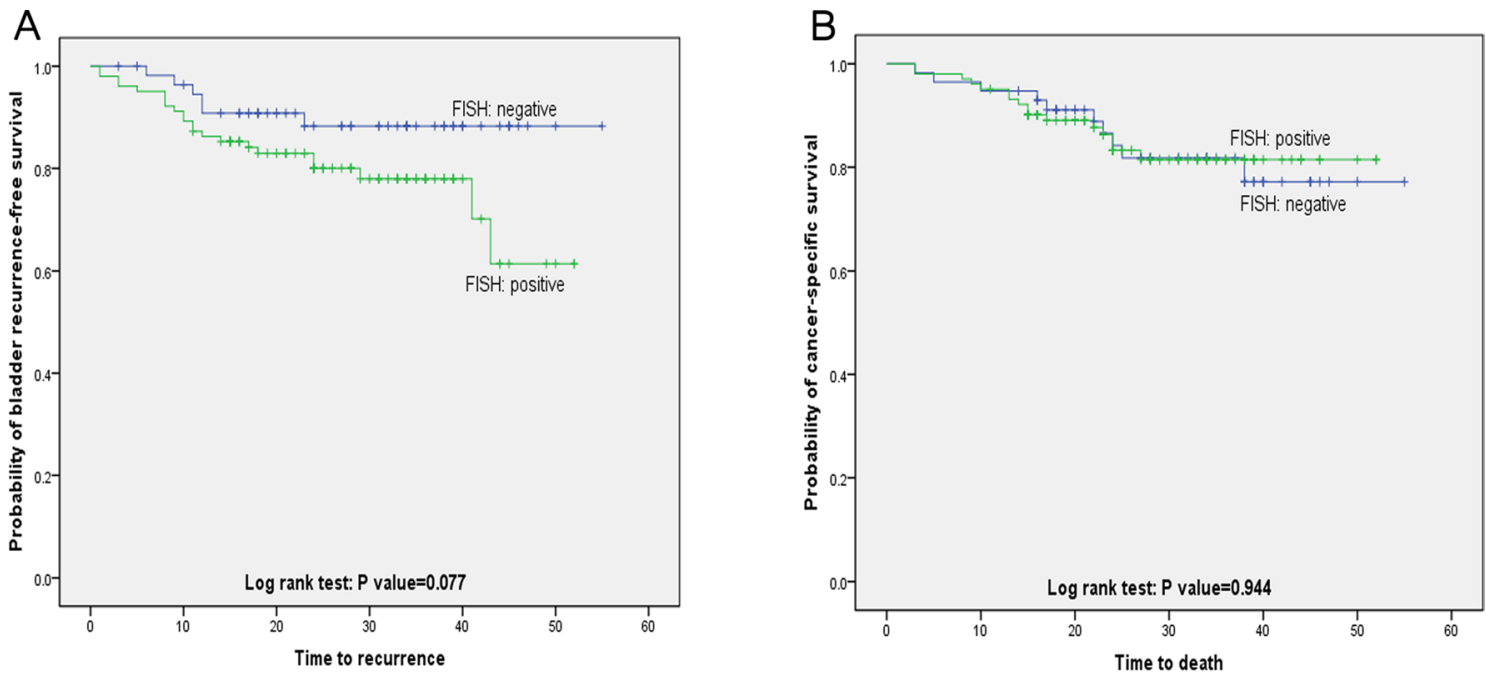

Figure 1: Bladder recurrence-free survival and cancer specific-free survival stratified by FISH result. (A) Kaplan-Meier plot of recurrence-free survival curves stratified by positive and negative FISH $(p=0.077)$. (B) Kaplan-Meier plot of cancer specific-free survival curves stratified by positive and negative FISH $(p=0.944)$.
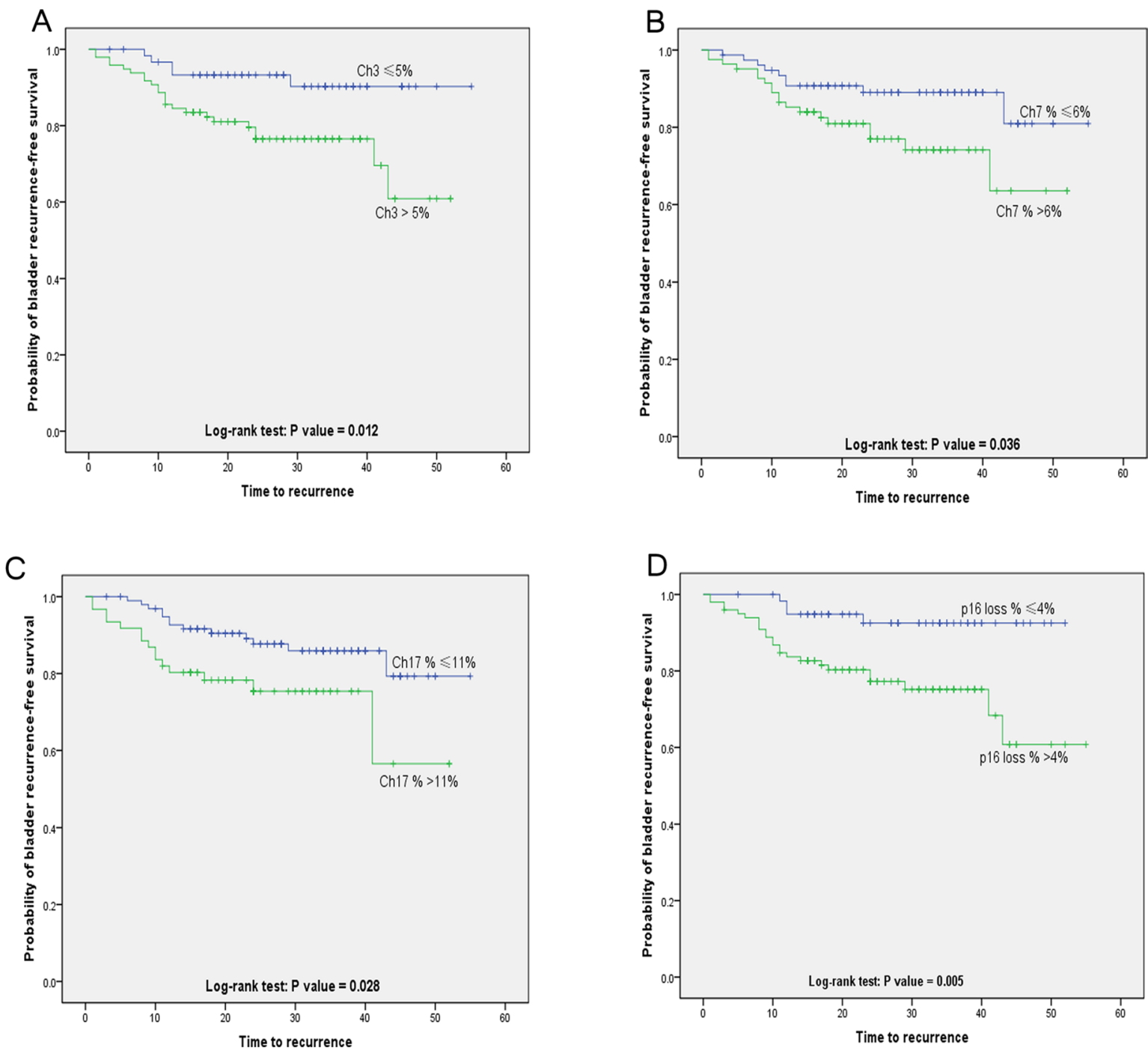

Figure 2: Kaplan-Meier plot of Bladder recurrence-free survival stratified by the percentage of copy number aberrations of (A) chromosomes 3 ( $p=0.012),(\mathbf{B})$ chromosomes $7(p=0.036),(\mathbf{C})$ chromosomes $17(p=0.028)$ and $(\mathbf{D})$ p16 loss $(p=0.005)$. 
Table 4: Univariate and multivariate analysis of CSS and BRFS

\begin{tabular}{|c|c|c|c|c|c|c|c|c|}
\hline \multirow[t]{3}{*}{ Variable } & \multicolumn{4}{|c|}{ CSS } & \multicolumn{4}{|c|}{ BRFS } \\
\hline & \multicolumn{2}{|c|}{ Univariate } & \multicolumn{2}{|c|}{ Multivariate } & \multicolumn{2}{|c|}{ Univariate } & \multicolumn{2}{|c|}{ Multivariate } \\
\hline & HR(95\%CI) & $P$ & HR(95\%CI) & $P$ & HR(95\%CI) & $\boldsymbol{P}$ & HR(95\%CI) & $P$ \\
\hline $\begin{array}{l}\text { Gender } \\
\text { Male } \\
\text { Female }\end{array}$ & $\begin{array}{l}2.131 \\
(0.949-4.782)\end{array}$ & 0.067 & & & $\begin{array}{l}1.823 \\
(0.852-3.901)\end{array}$ & 0.122 & & \\
\hline Age & $\begin{array}{l}0.999 \\
(0.960-1.038)\end{array}$ & 0.943 & & & $\begin{array}{l}0.975 \\
(0.942-1.009)\end{array}$ & 0.146 & & \\
\hline $\begin{array}{l}\text { Hydronephrosis } \\
\text { Present } \\
\text { Absent }\end{array}$ & $\begin{array}{l}1.490 \\
(0.512-4.336)\end{array}$ & 0.464 & & & $\begin{array}{l}1.199 \\
(0.411-3.497)\end{array}$ & 0.740 & & \\
\hline $\begin{array}{l}\text { Tumor location } \\
\text { Pelvis } \\
\text { Ureter } \\
\text { Both }\end{array}$ & $\begin{array}{l}1.709 \\
(0.906-3.224)\end{array}$ & 0.098 & & & $\begin{array}{l}1.297 \\
(0.690-2.439)\end{array}$ & 0.420 & & \\
\hline $\begin{array}{l}\text { Tumor stage } \\
\text { T1\&T2 } \\
\text { T3\&T4 }\end{array}$ & $\begin{array}{l}6.507 \\
(2.962-14.296)\end{array}$ & $<0.001$ & $\begin{array}{l}6.087 \\
(2.766-13.395)\end{array}$ & $<0.001$ & $\begin{array}{l}1.572 \\
(0.691-3.575)\end{array}$ & 0.281 & & \\
\hline $\begin{array}{l}\text { Tumor grade } \\
\text { High } \\
\text { Low }\end{array}$ & $\begin{array}{l}2.898 \\
(1.260-6.667)\end{array}$ & 0.012 & & & $\begin{array}{l}1.224 \\
(0.583-2.573)\end{array}$ & 0.593 & & \\
\hline $\begin{array}{l}\text { Lymph node } \\
\text { status } \\
\text { cN0 or pN0 } \\
\mathrm{N}+\end{array}$ & $\begin{array}{l}3.773 \\
(1.125-12.648)\end{array}$ & 0.031 & & & $\begin{array}{l}0.811 \\
(0.110-5.969)\end{array}$ & 0.837 & & \\
\hline $\begin{array}{l}\text { LVI } \\
\text { Presence } \\
\text { Absence }\end{array}$ & $\begin{array}{l}3.867 \\
(1.674-8.936)\end{array}$ & 0.002 & & & $\begin{array}{l}2.216 \\
(0.894-5.488)\end{array}$ & 0.086 & & \\
\hline $\begin{array}{l}\text { Tumor size } \\
\leq 3 \mathrm{~cm} \\
>3 \mathrm{~cm}\end{array}$ & $\begin{array}{l}2.730 \\
(1.214-6.137)\end{array}$ & 0.015 & $\begin{array}{l}2.425 \\
(1.077-5.458)\end{array}$ & 0.032 & $\begin{array}{l}0.915 \\
(0.428-1.957)\end{array}$ & 0.819 & & \\
\hline $\begin{array}{l}\text { Multifocal } \\
\text { Yes } \\
\text { No }\end{array}$ & $\begin{array}{l}1.889 \\
(0.758-4.709)\end{array}$ & 0.172 & & & $\begin{array}{l}3.808 \\
(1.756-8.258)\end{array}$ & 0.001 & $\begin{array}{l}3.487 \\
(1.605-7.576)\end{array}$ & 0.002 \\
\hline $\begin{array}{l}\text { Ch3 abnormal } \\
\leq 5 \% \\
>5 \%\end{array}$ & $\begin{array}{l}0.883 \\
(0.405-1.924)\end{array}$ & 0.754 & & & $\begin{array}{l}3.204 \\
(1.217-8.343)\end{array}$ & 0.018 & & \\
\hline $\begin{array}{l}\text { Ch7 abnormal } \\
\leq 6 \% \\
>6 \%\end{array}$ & $\begin{array}{l}0.762 \\
(0.349-1.662)\end{array}$ & 0.494 & & & $\begin{array}{l}2.283 \\
(1.029-5.065)\end{array}$ & 0.042 & & \\
\hline $\begin{array}{l}\text { Ch17 abnormal } \\
\leq 11 \% \\
>11 \%\end{array}$ & $\begin{array}{l}1.386 \\
(0.634-3.030)\end{array}$ & 0.413 & & & $\begin{array}{l}2.260 \\
(1.070-4.774)\end{array}$ & 0.033 & & \\
\hline $\begin{array}{l}\mathrm{p} 16 \text { loss } \\
\leq 4 \% \\
>4 \%\end{array}$ & $\begin{array}{l}2.288 \\
(0.918-5.706)\end{array}$ & 0.076 & & & $\begin{array}{l}4.065 \\
(1.410-11.718)\end{array}$ & 0.009 & $\begin{array}{l}3.766 \\
(1.303-10.884)\end{array}$ & 0.014 \\
\hline
\end{tabular}

CSS: Cancer Specific-free Survival; BRFS: Bladder Recurrence-free Survival; LVI: lymphovascular invasion; CH: chromosome. 
wash samples of patients with NMIBC and found that 9p21 loss larger than $12 \%$ was a predictive factor for relapse. Zellweger and his research team [27] found that the loss of p16 was expressively related to bladder relapse. Kawauchi and his colleagues [28] confirmed that a 9p21 index was an independent prognostic factor for bladder recurrence in patients with urothelial carcinoma. Although the p16 site was one of the most common genetic mutations in urothelial carcinoma [29], but our results were paradoxical. Traditionally, a tube of urine sample was diagnosed FISH with positive result in patients with urothelial tumor if at least 12 cells $(12 \%)$ with homozygous p16 deletions were identified, but we set $4 \%$ as cutoff values of p16 loss based on AUC from ROC for recurrence. One possible explanation for our finding may be that p16 genetic aberrations of Chinese UTUC patients were relatively low compared with western country, hence the possibility of p16 loss we could detect from voided urine was comparatively low (median of p16: 7\%). Consequently, p16 was a special characteristic for Chinese UTUC patients and its clinical significance should be taken into consideration.

Our study also has some limitations.. First of all, the present study was confined due to its retrospective features and considerably small sample size. In addition, the FISH approach might present with interobserver evaluation diversity and diverse specimens quality. Despite these limitations, this is the first report so far of the capacity of FISH to assess its predictive value for UTUC bladder recurrence. Although a multicenter perspective cohort study with longer follow-up period should be performed to identify these research results, our study group found that preoperative FISH probe data could not only be used as a diagnostic tool and predict UTUC tumor malignant behavior, but also could be used as a prognostic tool.

\section{MATERIALS AND METHODS}

\section{Patient selection}

A total of 232 consecutive patients who underwent surgeries for UTUC in the Urology Department, Peking University First Hospital between January 2012 and May 2016 were enrolled in this study. Seventy-three were subsequently removed from the analysis: 22 patients with previous or concomitant bladder tumors; 36 patients failed to follow up; 15 patients without information of FISH probe. Clinicopathologic data for the remaining 159 patients were retrospectively analyzed. None of the patients had received neoadjuvant chemotherapy. All patients provided written informed consent.

\section{FISH, treatment strategy and pathological evaluation}

Voided urine specimens from the 159 UTUC patients were analyzed using UroVysion FISH kit; labeled probes specific for chromosomes 3, 7, and 17, and the p16 (9p21) genes were used to assess prognostic value. About $45 \mathrm{ml}$ urine of each patient was collected using a $50 \mathrm{ml}$ sterile centrifuge tube from 8:00 to 11:00 in the morning. The FISH assays were ordered based on provider's protocol. Diagnosis criteria for positive FISH was described as previous study [8]. All UTUC patients who underwent conservative surgery or RNU were regularly followed according to institutional practice. In this cohort, one hundred and forty-two patients underwent RNU with an ipsilateral bladder cuff excision; the remaining 17 patients underwent conservative surgery, including ureteroureterostomy and complete distal ureterectomy and neocystostomy. All pathological specimens were reexamined by a dedicated genitourinary pathologist to confirm the original diagnosis. Tumor stage, grade, multifocality, tumor size and status of regional lymph nodes were described as previous study [8].

\section{Follow-up}

Follow-up including laboratory data, chest X-ray, urinary ultrasonography, computed tomography/magnetic resonance imaging and cystoscopic evaluation of the urinary bladder should be made every 3 months for the first 2 years, every 6 months until year 5 , then annually. The co-primary endpoints of the study were bladder recurrence and cancer-specific death. Bladder recurrence was defined as finding bladder tumors at cystoscopic evaluation and the patients were performed transurethral resection of bladder tumor or radical cystectomy thereafter. Bladder recurrencefree survival (BRFS) and cancer-specific survival (CSS) were calculated from the date of surgery to the date of bladder recurrence and cancer specific death.

\section{Statistical analysis}

We used Mann-Whitney $U$ and chi-squared tests to compare continuous and categorical variables, respectively. Binary logistic regression was used to evaluate preoperative factors. The probability of survival was calculated by the Kaplan-Meier method, with statistical differences evaluated by the log-rank test. Variables influencing BRFS and CSS were compared using Cox proportional hazards regression models. Variables with a $p<0.05$ in univariate analysis were also assessed in multivariate analysis. All statistical analyses were performed using the IBM Statistical Package for Social Sciences (SPSS) version 22.0. For all statistical tests, two-sided $p<0.05$ was considered to indicate statistical significance.

\section{Author contributions}

Bao Guan, Congyi Du and Xiaohong Su are co-frst authors and contributed equally to the study. Liqun Zhou 
and Xuesong Li are corresponding authors and contributed to the overall study design. Zhenpeng Cao, Yifan Li, Yonghao Zhan, Ding Peng, Gengyan Xiong, Dong Fang, Yi Ding, Shiming He, Yanqing Gong, Qun He conduced to data collection, and analysis.

\section{CONFLICTS OF INTEREST}

The authors declare no conflicts of interest.

\section{FUNDING}

This work was supported by grants from the Natural Science Foundation of Beijing (7152146), the Clinical Features Research of the Capital (No. Z151100004015173) and the Capital Health Research and Development of Special (2016-1-4077).

\section{REFERENCES}

1. Roupret M, Babjuk M, Comperat E, Zigeuner R, Sylvester RJ, Burger M, Cowan NC, Bohle A, Van Rhijn BW, Kaasinen E, Palou J, Shariat SF. European Association of Urology Guidelines on Upper Urinary Tract Urothelial Cell Carcinoma: 2015 Update. Eur Urol. 2015; 68:868-79. https://doi.org/10.1016/j.eururo.2015.06.044.

2. Lughezzani G, Burger M, Margulis V, Matin SF, Novara G, Roupret M, Shariat SF, Wood CG, Zigeuner R. Prognostic factors in upper urinary tract urothelial carcinomas: a comprehensive review of the current literature. Eur Urol. 2012; 62:100-14. https://doi.org/10.1016/j.eururo.2012.02.030.

3. Xylinas E, Rink M, Margulis V, Karakiewicz P, Novara G, Shariat SF, Upper Tract Urothelial Carcinoma Collaboration. Multifocal carcinoma in situ of the upper tract is associated with high risk of bladder cancer recurrence. Eur Urol. 2012; 61:1069-70. https://doi.org/10.1016/j.eururo.2012.02.042.

4. Wang J, Wu J, Peng L, Tu P, Li W, Liu L, Cheng W, Wang X, Zhou S, Shi S, Ma H, Lu G, Zhou X. Distinguishing urothelial carcinoma in the upper urinary tract from benign diseases with hematuria using FISH. Acta Cytol. 2012; 56:533-8. https://doi.org/10.1159/000341622.

5. Xu C, Zeng Q, Hou J, Gao L, Zhang Z, Xu W, Yang B, Sun Y. Utility of a modality combining FISH and cytology in upper tract urothelial carcinoma detection in voided urine samples of Chinese patients. Urology. 2011; 77:636-41. https://doi.org/10.1016/j.urology.2010.07.498.

6. Whitson J, Berry A, Carroll P, Konety B. A multicolour fluorescence in situ hybridization test predicts recurrence in patients with high-risk superficial bladder tumours undergoing intravesical therapy. BJU Int. 2009; 104:336-9. https://doi.org/10.1111/j.1464-410X.2009.08375.x.

7. Lodde M, Mian C, Mayr R, Comploj E, Trenti E, Melotti R, Campodonico F, Maffezzini M, Fritsche HM, Pycha A. Recurrence and progression in patients with non-muscle invasive bladder cancer: prognostic models including multicolor fluorescence in situ hybridization molecular grading. Int J Urol. 2014; 21:968-72. https://doi.org/10.1111/ iju.12509.

8. Su X, Hao H, Li X, He Z, Gong K, Zhang C, Cai L, Zhang Q, Yao L, Ding Y, Gong Y, Fang D, Zhang Z, et al. Fluorescence in situ hybridization status of voided urine predicts invasive and high-grade upper tract urothelial carcinoma. Oncotarget. 2017; 8:26106-11. https://doi. org/10.18632/oncotarget.15344.

9. Garcia-Pelaez B, Trias I, Roman R, Pubill C, Banus JM, Puig X. Fluorescent in situ hybridization as a predictor of relapse in urothelial carcinoma. Actas Urol Esp. 2013; 37:395-400. https://doi.org/10.1016/j.acuro.2012.11.005.

10. Matsuyama H, Ikemoto K, Eguchi S, Oga A, Kawauchi S, Yamamoto Y, Kawai Y, Matsumoto H, Hara T, Nagao K, Sakano S, Sasaki K. Copy number aberrations using multicolour fluorescence in situ hybridization (FISH) for prognostication in non-muscle-invasive bladder cancer (NIMBC). BJU Int. 2014; 113:662-7. https://doi. org/10.1111/bju.12232.

11. Seideman C, Canter D, Kim P, Cordon B, Weizer A, Oliva I, Rao J, Inman BA, Posch M, Herr H, Lotan Y. Multicenter evaluation of the role of UroVysion FISH assay in surveillance of patients with bladder cancer: does FISH positivity anticipate recurrence? World J Urol. 2015; 33:1309-13. https://doi.org/10.1007/s00345-014-1452-9.

12. Babjuk M, Bohle A, Burger M, Capoun O, Cohen D, Comperat EM, Hernandez V, Kaasinen E, Palou J, Roupret M, van Rhijn BW, Shariat SF, Soukup V, et al. EAU Guidelines on Non-Muscle-invasive Urothelial Carcinoma of the Bladder: Update 2016. Eur Urol. 2017; 71:447-61. https://doi.org/10.1016/j.eururo.2016.05.041.

13. Ku JH, Moon KC, Jung JH, Jeong SH, Kwak C, Kim HH. External validation of an online nomogram in patients undergoing radical nephroureterectomy for upper urinary tract urothelial carcinoma. Br J Cancer. 2013; 109:1130-6. https://doi.org/10.1038/bjc.2013.462.

14. Roupret M, Hupertan V, Seisen T, Colin P, Xylinas E, Yates DR, Fajkovic H, Lotan Y, Raman JD, Zigeuner R, Remzi M, Bolenz C, Novara G, et al. Prediction of cancer specific survival after radical nephroureterectomy for upper tract urothelial carcinoma: development of an optimized postoperative nomogram using decision curve analysis. J Urol. 2013; 189:1662-9. https://doi.org/10.1016/j. juro.2012.10.057.

15. Seisen T, Colin P, Hupertan V, Yates DR, Xylinas E, Nison L, Cussenot O, Neuzillet Y, Bensalah K, Novara G, Montorsi F, Zigeuner R, Remzi M, et al. Postoperative nomogram to predict cancer-specific survival after radical nephroureterectomy in patients with localised and/or locally advanced upper tract urothelial carcinoma without metastasis. BJU Int. 2014; 114:733-40. https://doi. org/10.1111/bju.12631.

16. Yates DR, Hupertan V, Colin P, Ouzzane A, Descazeaud A, Long JA, Pignot G, Crouzet S, Rozet F, Neuzillet 
Y, Soulie M, Bodin T, Valeri A, et al. Cancer-specific survival after radical nephroureterectomy for upper urinary tract urothelial carcinoma: proposal and multiinstitutional validation of a post-operative nomogram. Br J Cancer. 2012; 106:1083-8. https://doi.org/10.1038/ bjc.2012.64.

17. Luo HL, Kang CH, Chen YT, Chuang YC, Lee WC, Cheng YT, Chiang PH. Diagnostic ureteroscopy independently correlates with intravesical recurrence after nephroureterectomy for upper urinary tract urothelial carcinoma. Ann Surg Oncol. 2013; 20:3121-6. https://doi. org/10.1245/s10434-013-3000-z.

18. Liu P, Su XH, Xiong GY, Li XS, Zhou LQ. Diagnostic Ureteroscopy for Upper Tract Urothelial Carcinoma is Independently Associated with Intravesical Recurrence after Radical Nephroureterectomy. Int Braz J Urol. 2016; 42:1129-35. https://doi.org/10.1590/S1677-5538. IBJU.2015.0366.

19. Tanaka N, Kikuchi E, Kanao K, Matsumoto K, Shirotake S, Kobayashi H, Miyazaki Y, Ide H, Obata J, Hoshino K, Hayakawa N, Kosaka T, Oyama M, et al. The predictive value of positive urine cytology for outcomes following radical nephroureterectomy in patients with primary upper tract urothelial carcinoma: a multi-institutional study. Urol Oncol. 2014; 32: 48 e19-26. https://doi.org/10.1016/j. urolonc.2013.07.003.

20. Kobayashi Y, Saika T, Miyaji Y, Saegusa M, Arata R, Akebi N, Takenaka T, Manabe D, Nasu Y, Kumon H. Preoperative positive urine cytology is a risk factor for subsequent development of bladder cancer after nephroureterectomy in patients with upper urinary tract urothelial carcinoma. World J Urol. 2012; 30:271-5. https://doi.org/10.1007/ s00345-011-0731-y.

21. Maffezzini M, Campodonico F, Capponi G, Canepa G, Casazza S, Bandelloni R, Tamagno S, Puntoni M. Prognostic significance of fluorescent in situ hybridisation in the follow-up of non-muscle-invasive bladder cancer. Anticancer Res. 2010; 30:4761-5.
22. Habuchi T. Origin of multifocal carcinomas of the bladder and upper urinary tract: molecular analysis and clinical implications. Int J Urol. 2005; 12:709-16. https://doi. org/10.1111/j.1442-2042.2005.01155.x.

23. Habuchi T, Takahashi R, Yamada H, Kakehi Y, Sugiyama T, Yoshida O. Metachronous multifocal development of urothelial cancers by intraluminal seeding. Lancet. 1993; 342:1087-8.

24. Yeager T, Stadler W, Belair C, Puthenveettil J, Olopade O, ReznikoffC. Increased p16 levels correlate with $\mathrm{pRb}$ alterations in human urothelial cells. Cancer Res. 1995; 55:493-7.

25. Piaton E, Carre C, Advenier AS, Decaussin-Petrucci M, Mege-Lechevallier F, Lantier P, Granier G, Ruffion A. p16 INK4a overexpression and p16/Ki-67 dual labeling versus conventional urinary cytology in the evaluation of urothelial carcinoma. Cancer Cytopathol. 2014; 122:211-20. https:// doi.org/10.1002/cncy.21376.

26. van Rhijn BW, Burger M, Lotan Y, Solsona E, Stief CG, Sylvester RJ, Witjes JA, Zlotta AR. Recurrence and progression of disease in non-muscle-invasive bladder cancer: from epidemiology to treatment strategy. Eur Urol. 2009; 56:430-42. https://doi.org/10.1016/j.eururo.2009.06.028.

27. Zellweger T, Benz G, Cathomas G, Mihatsch MJ, Sulser T, Gasser TC, Bubendorf L. Multi-target fluorescence in situ hybridization in bladder washings for prediction of recurrent bladder cancer. Int J Cancer. 2006; 119:1660-5. https://doi.org/10.1002/ijc.21704.

28. Kawauchi S, Sakai H, Ikemoto K, Eguchi S, Nakao M, Takihara H, Shimabukuro T, Furuya T, Oga A, Matsuyama H, Takahashi M, Sasaki K. 9p21 index as estimated by dual-color fluorescence in situ hybridization is useful to predict urothelial carcinoma recurrence in bladder washing cytology. Hum Pathol. 2009; 40:1783-9. https://doi. org/10.1016/j.humpath.2009.06.011.

29. Cairns P, Shaw ME, Knowles MA. Initiation of bladder cancer may involve deletion of a tumour-suppressor gene on chromosome 9. Oncogene. 1993; 8:1083-5. 